\title{
Ecos y tensiones de la tradición anticolonialista latinoamericana en las reflexiones de los feminismos descoloniales y antirracistas: ¿Cómo pensar el género sin reproducir sus violencias?
}

Echoes and tensions of the latin american anticolonialist tradition in the reflections of the decolonial and anti-racist feminisms: How can gender be thought without reproducing its violence?

Panchiba F. Barrientos*

\section{Resumen}

El feminismo, como variable analítica y epistemológica, se integra cada vez con más fuerza en nuevos espacios de pensamiento y reflexión crítica, abriendo la posibilidad de imaginar nuevas configuraciones sociales en las cuales las diferencias entre hombres y mujeres ya no sean articuladas o experimentadas en términos de desigualdad. ¿Qué sentido tiene pensar la colonialidad y sus potencias en una clave feminista? ¿Cómo pensar las identidades mujer/mujeres desde una perspectiva que ponga en tensión el género y las tradiciones del pensamiento anticoloniales?

¿Es posible pensar en la colonialidad desde una clave de género? ¿Es posible desdoblar el género y librarnos de las normas que muchas veces se levantan desde los discursos que han venido a rescatarnos?

Palabras clave: Feminismos descoloniales, género, identidad, tradición anticolonial.

\begin{abstract}
Feminism, as an analytical and epistemological variable, proposes critical and reflection that opens the possibility of imagining new social configurations in which the differences between men and women are no longer articulated or experienced in terms of inequality. Can we think coloniality and its powers in a feminist key? How to think of woman/ women identities from a perspective that puts the gender and anticolonial traditions of thought? Is it possible to think of coloniality from a gender perspective? Is it possible to split the gender and get rid of the rules that often arise from the speeches that have come to rescue us?
\end{abstract}

Key words: Decolonial feminisms, gender, identity, anticolonial tradition.

Fecha de recepción: 20 de agosto 2015

Fecha de aprobación: 21 de marzo 2017

\footnotetext{
* Magister en historia, Universidad de Chile
} 
La apropiación de la historia por parte de los feminismos de las mujeres blancas ha despojado de su propia historia a los otros feminismos. Apropiándose de la memoria histórica se apropian también de la definición de la opresión así como del diseño de las estrategias políticas transformadoras. Anulando las historias particulares inventan una sola historia, la que ha protagonizado el movimiento feminista blanco desde el periodo ilustrado $^{1}$

Cuando digo «desde el cual» (en el sentido de ubicación espacial y temporal) supongo que el conocimiento no es algo que se produce desde un no-lugar posmoderno; por el contrario, el conocimiento siempre tiene una ubicación geohistórica y geopolítica en la diferencia epistémica colonial. Por esa razón, la geopolítica del conocimiento es una perspectiva necesaria para que se desvanezca el supuesto eurocéntrico de que el conocimiento válido y legítimo se mide de acuerdo con parámetros occidentales ${ }^{2}$

En los últimos cuarenta años, el concepto de género se ha insertado con potencia en distintas áreas de las ciencias sociales, las humanidades y el pensamiento político. Género ha sido entendido como una herramienta discursiva que viene a poner en evidencia las desigualdades surgidas al alero de la diferenciación y ordenación sexual de los sujetos, abriendo la posibilidad de imaginar nuevas configuraciones sociales en las cuales las diferencias entre hombres y mujeres ya no sean articuladas o experimentadas en términos de desigualdad.

Sin embargo, el entusiasmo con el que el concepto de género ha sido recibido y la fuerza con la que se instaló en diversos espacios de pensamiento y acción política, viene siendo contestado, de un tiempo a esta parte, por un amplio contingente de activistas y teóricas feministas que ven en él una peligrosa re-organización de las normas.

Desde comienzos de los años ochenta del siglo pasado -con distintos registros y desde lugares muy diversos- un amplio contingente de investigadoras y teóricas feministas han insistido en la necesidad de revisar el concepto género, asumiendo que éste no es nunca una articulación trasparente, sino que más bien, se encuentra siempre atravesado por estructuras simbólicas y de poder que al mismo tiempo lo constituyen y lo exceden. Podemos decir, a grandes rasgos, que estos desarrollos críticos de la noción de género han buscado dar cuenta de la urgencia de comprender la compleja relación que se tiende entre este concepto y el binomio naturaleza/cultura, han puesto de relieve la importancia de pensar la posibilidad de incorporar preguntas sobre la especificidad de la experiencia a la hora de pensar el género y sus efectos normativos $y$, también, se han propuesto repensar y desplazar los impactos de esta categoría en los procesos de formación de nuestras articulaciones subjetivas.

\footnotetext{
1 Jabardo, Mercedes (ed.). 2012. Feminismos negros. Una antología, Madrid: Traficantes de sueños. p.14.

${ }^{2}$ Mignolo, Walter. 2005/ 2007. La idea de América Latina. La herida colonial y la opción decolonial.

Barcelona: Gedisa. p.66.
} 
Pareciera ser que la fuerza de la idea de género, en tanto categoría analítica, está lejos de detenerse, ya que este concepto sigue abriéndose paso en nuevos espacios de pensamiento y reflexión crítica, entre los cuales pensamiento anticolonial latinoamericano no es la excepción.

¿Qué conexiones existen, surgen y se tienden entre los pensamientos desarrollados al amparo de la amplia tradición anticolonial latinoamericana y las miradas feministas descoloniales más actuales? ¿Qué sentido tiene pensar la colonialidad y sus potencias en una clave feminista, siguiendo los planteamientos de autoras como María Lugones, Yuderkis Espinosa, Karina Bidaseca y Rita Laura Segato? ¿Cómo pensar el género y las identidades mujer/mujeres desde una perspectiva crítica que surja a partir de una revisión de la propia tradición anticolonial?

Los debates que se levantan en torno a estas preguntas son tremendamente actuales y se encuentran anclados en el corazón de los movimientos feministas y de mujeres en Chile y América Latina, esto, por lo tanto, nos obliga a detenernos y a revisar la importancia de desdoblar los márgenes de las posiciones identitarias y sus implicancias para la articulación de nuevos sujetos políticos más allá del género, a partir de una serie de preguntas como las que siguen: ¿Cuáles son los cuerpos del feminismo? ¿Qué es una política de género? ¿Quién puede definirse como un sujeto feminista?

En este texto quiero reflexionar, desde una perspectiva interseccional y feminista, en torno a las preguntas que se despliegan cuando pensamos en la colonialidad desde una mirada de género. Quiero pensar qué ocurre cuando reflexionamos sobre las formas en que los procesos de racialización se reinscriben sobre los cuerpos de hombres y mujeres, en un horizonte cultural en el que la otredad tiende a ser feminizada y la diferencia se invisibiliza en pos de un universal supuestamente neutro, pero que en realidad opera una doble articulación de encubrimiento, a partir de la cual silencia lo que no se le parece y atenta contra las posibilidades de existencia de aquello que no comprende.

A lo largo de este trabajo buscaré reflexionar en torno a los modos en los que los pensamientos feministas que se construyen a sí mismos a partir de miradas críticas de las dependencias coloniales y neocoloniales que aún operan en nuestros territorios, se insertan en el horizonte del pensamiento anticolonial latinoamericano, que es, al mismo tiempo, una tradición que los configura, los interpela y los excede.

¿Puede el feminismo descolonial -entendido como un horizonte de reflexión que "elabora una genealogía del pensamiento producido desde los márgenes por feministas, mujeres, lesbianas y gente racializada en general; y dialoga con los conocimientos generados por intelectuales y activistas comprometidos con desmantelar la matriz de opresión múltiple asumiendo un punto de vista no eurocentrado" (Espinosa, Yuderkys: 2014, 7)- abrir nuevos caminos y posibilidades de transformación radical, para repensar nuestras experiencias como mujeres que habitan antiguos territorios colonizados en los los que las 
matrices subjetivas de la colonialidad del saber y del poder poder aún continúan vigentes (Quijano, Aníbal: 2001)?

¿Podemos imaginarnos experiencias, representaciones y subjetividades que surjan más allá de los marcos institucionales del género que han operado -y al mismo tiempo han sido producidos- a partir de los procesos de colonización que ha enfrentado nuestro continente $\mathrm{o}$, es que acaso la forma en que este concepto ha sido utilizado y referido por autores como Aníbal Quijano y Walter Mignolo estaría, de cierta manera, contribuyendo a la rearticulación de algunas formas de violencia?

\section{Una voz múltiple recorre América: El pensamiento anticolonialista como tradición heterodoxa}

A la hora de pensar en torno a América Latina y el Caribe -en tanto que espacios simbólicos de enunciación y lugares geolípolíticos de reivindicación social, material e imaginaria- debemos comprender que estos espacios no conforman un horizonte de sentido plano, unívoco o acabado al cual podamos acceder sin dificultades y de manera total. Antes bien, ellos articulan las coordenadas de un universo de significados en disputa, a partir de los cuales lo nombrado, lo visto, el pasado y el presente son resignificados, a partir de complejos entramados de discursos entretejidos, mediante los que dialogan distintas memorias, saberes, ficciones y sentidos de lo político.

¿Qué es América y cuándo surge? ¿Cuáles son los países, naciones y territorios a los que hacemos referencia cuando intentamos pensar lo americano y lo caribeño? Quizás basten estas preguntas para dar cuenta de las inmensas profundidades políticas, normativas, materiales e ideológicas en las que hunden sus raíces las reflexiones que aquí nos convocan. Es necesario insistir, que sobre ninguna de estas interrogantes está dicha la última palabra, puesto que todas pueden ser respondidas desde lugares múltiples, y que los cimientos que sostienen a nuestras posibles respuestas se encuentran en un constante proceso de movimiento y resignificación.

América no es una palabra libre de cargas y, por lo tanto, el sólo hecho de utilizar este nombre para denominar los territorios que habitamos, muchas veces puede producir episodios de violencia epistémica, toda vez que desde aquí se invisibilizan los esfuerzos por pensar con otros nombres este continente imaginaria y políticamente disputado. La potencia performativa que emana del uso del nombre América, jamás debe ser pasada por alto u olvidada. A modo de ejemplo, podemos pensar aquí en las reflexiones que ha propuesto Walter Mignolo sobre la articulación de lo americano como un dispositivo ideológico y político que, luego de los viajes de Colón y a partir de la conquista y la colonización del continente, renovó los límites y las características del sistema-economíamundo. Así, según la propuesta de Mignolo "la «idea» de América fue una invención europea que eliminó las denominaciones dadas por los pueblos que habían vivido en el continente durante siglos antes de que Colón lo «descubriera». El fenómeno ha sido definido como "deculturación», "desposesión» (material y espiritual), y en épocas más 
recientes, como "colonización del saber» y "colonización del ser»". (Mignolo, Walter. 2005/ 2007. p.47)

Siempre debemos tener presente que no hay nada permanente ni obvio en la enunciación de lo americano. América no existe en estado salvaje y no puede ser comprendida al margen de aquella serie de discursos que le han dado forma desde hace siglos. Esos discursos le han asignado a América y a lo americano un lugar en el horizontemundo moderno, una forma de estar en el mundo, una razón y un tiempo específicos desde el cual pareciera ser que todo adquiere sentido.

Resulta fundamental atrevernos a reflexionar en torno a otras formas de representación y articulación de América y lo americano, a través de las cuales los espacios centrales del discurso sobre nuestro continente y sobre nosotros mismos sean contestados, disputados y desmontados a partir de la visibilización de los andamiajes de poder y control que se han levantado sobre nuestros cuerpos y territorios. En atención a lo anterior, resulta tremendamente interesante recordar las palabras de Aníbal Quijano, quien en 1992, en su texto La americanidad como concepto o América en el mundo moderno-colonial, proponía que "el moderno sistema mundial nació a lo largo del Siglo XVI. América -como entidad neosocial- nació a lo largo del siglo XVI. La creación de esta entidad neosocial, América, fue el acto constitutivo del moderno sistema mundial. América no se incorporó en una ya existente economía-mundo capitalista. Una economía-mundo capitalista no hubiera tenido lugar sin América." (Quijano, Aníbal: 1992, 71) 3 .

¿Cómo podríamos pensar América o lo americano sin pasar por aquellas definiciones impuestas desde Europa Central en las cuales nuestro continente queda situado como margen, como espacio para la explotación de recursos y mano de obra o, incluso, como límite mágico articulado más allá del mundo?

Distintas trayectorias del pensamiento latinoamericano y sus desarrollos críticos respecto a los procesos de construcción simbólica y discursiva de América -así como también de los conflictos derivados de la dependencia colonial y neocolonial en nuestro continente- dan cuenta de una historia epistemológica que hunde sus raíces en el compromiso político de transformar imaginaria y materialmente las miradas que surgen a la hora de pensar América más allá de los lugares que le han sido asignados, es decir, estableciendo un quiebre con los imaginarios del orden-mundo de la modernidad europea. Sobre este

\footnotetext{
${ }^{3}$ Esta idea es retomada por la teórica feminista Silvia Federicci, en su libro Calibán y la Bruja. Mujeres Cuerpo y acumulación originaria (Federicci, Silvia. 2011). Federicci se atreve a llevar sus preguntas hacia un horizonte radical, marcado por tres elementos fundamentales que dan cuenta de los desplazamientos imaginarios, políticos y económicos del período: 1.- la usurpación y el despojo de los saberes de las mujeres; 2.- el desplazamiento de éstas de los espacios públicos y su confinamiento en los espacios ligados únicamente a lo privado y; 3.- la desvaloración/apropiación del cuerpo de las mujeres (y de los indígenas feminizados). Así, Federicci ofrece una mirada crítica en la que la colonización americana y el desarrollo del capitalismo en sus primeras etapas, van acompañados necesariamente de una profundización de las diferencias entre hombres y mujeres, las cuales fueron articuladas en términos de género y de desigualdad, y cuyos efectos son apreciables y siguen siendo producidos y perpetuados aún hoy.
} 
punto, la historiadora de las ideas Francesca Gargallo, en su texto Feminismos desde Abya Yala. Ideas y proposiciones de las mujeres de 607 pueblos en nuestra América, da cuenta de la importancia del reconocimiento de otras modernidades y otros tiempos históricos que sean configurados desde hitos, miradas y discursos no hegemónicos, señalando que: "urge el estudio de las Modernidades que en América son herederas de civilizaciones campesinas, de naciones nómadas y de desarrollos urbanos y nacionales, que perviven y se recrean en la actualidad, aunque fueron avasalladas, incendiadas y casi destruidas durante la invasión y la colonización europeas del continente." (Gargallo, Francesca: 2012/ 2014, 23)

Los desarrollos teóricos propuestos en el horizonte del conjunto de pensamientos críticos entre los que podemos identificar a todxs aquellxs autorxs ${ }^{4}$ cuya preocupación ha estado relacionada con la necesidad de repensar lo local y sus resabios coloniales y neocoloniales, pueden ser enmarcados -más allá de las obvias diferencias temáticas, estilísticas y temporales- en un horizonte amplio que ha sido denominado pensamiento anticolonial.

Si bien es cierto, lo anticolonial hace referencia a un momento histórico específico y da cuenta de ciertas intenciones políticas y críticas bien definidas -que incluso bajo determinadas circunstancias podríamos pensar en pugna con otros saberes y posicionamientos críticos, como por ejemplo aquellos surgidos a partir de las nociones de subalternidad, poscolonialidad, y descolonialidad-, para el desarrollo de este texto asumiré el riesgo de pensar lo anticolonial no tanto como un momento específico del desarrollo del pensamiento político en nuestros territorios del sur, sino más bien como una tradición reflexiva en constante revisión y ampliación que ha dado forma a un tipo de sentido crítico que recorre América Latina y el Caribe.

Lo anticolonial será, desde aquí, una posibilidad de enunciación y una tradición epistemológica en la cual es posible insertar a una amplia y variada gama de autorxs que manifiestan la necesidad de pensar lo americano más allá de las lógicas de la dependencia y la subordinación. En el marco de este horizonte amplio e inclusivo, encontraremos a una serie de pensadorxs comprometidxs políticamente, que alzan la voz y levantan sus plumas afiladas para plantear reflexiones críticas en torno a los procesos de racialización de las poblaciones de nuestro continente, a las desigualdades surgidas al alero de las lógicas productivas y económicas coloniales/neocoloniales, a las disputas territoriales ligadas al despojo de las tierras indígenas, al colonialismo interno y a la conformación de

\footnotetext{
${ }^{4}$ Breve advertencia sobre la sustitución de algunas vocales finales que actúan como marcas de género: A lo largo de este texto sustituiré por una letra " $x$ " algunas vocales finales que actúan como marcas de género (a saber a/o/as/os), con la intención de no diluir en el supuesto de un universal inclusivo y sin marcas, aquellos agenciamientos y esfuerzos de identidades otras cuyo reconocimiento resulta vital para abrir paso a nuevas formas de mirar el mundo y reconocernos. Puede revisarse una interesante mirada sobre la utilidad de desmantelar las vocales - como espacio de asentamiento de las normas de género en el lenguaje- en la presentación del libro Interdicciones. Escrituras de la intersexualidad en castellano, de Mauro Cabral:

- Cabral, Mauro (ed.). 2009. Interdicciones. Escrituras de la intersexualidad en castellano, Córdoba: Mulabi
} 
estructuras nacionales perversas que no han desmantelado las redes de privilegios de las antiguas elites surgidas en la colonia, entre otros problemas, que aún hoy atraviesan nuestros territorios y que han sido parte fundamental de la historia de las luchas políticas desarrolladas a lo largo y ancho de nuestro continente.

El universo de preocupaciones y temáticas abordado bajo el manto del pensamiento anticolonial es tremendamente variado y complejo, puesto que, a partir de él, se entrecruzan una serie de preguntas que tienen que ver con la actualidad de lo colonial, con las luchas por el rescate de saberes que se desmarquen de los discursos hegemónicos eurocentrados, con las búsquedas que se esfuerzan por encontrar nuevos lugares y formas para narrar lo latinoamericano y con un conjunto de reflexiones que interrogan el pasado y el presente en un movimiento de continuidad y larga duración, en el cual se vuelve evidente que los procesos de colonización siguen operando con distintas intensidades al interior de nuestros territorios y también dentro de nosotrxs mismxs.

Un conjunto de voces tremendamente potentes y movilizadoras han recorrido nuestro territorio americano desde fines del siglo XIX y hasta hoy, revisitando las fronteras, los saberes y nuestras propias ideas de quiénes somos. Dentro de nuestro continente ha surgido una tradición de pensamiento que se revela contra el colonialismo en sus distintas formas, un pensamiento anticolonial de larga data que se inscribe en un campo intelectual politizado, que conforma un horizonte ético que busca comprometerse con la realidad para transformarla.

Así, desde el pensamiento pionero del escritor y periodista cubano José Martí, que quedó plasmado en Nuestra América como una voz de denuncia que aún hoy nos recuerda que "la colonia continuó viviendo en la[s] república[s]" (Martí, José. 1891/2005. p.35), hasta las posturas de autorxs como María Lugones, Silvia Ribera Cusicanqui, Walter Mignolo, Aníbal Quijano y todxs aquellxs que hoy -más allá de las distancias y las diferencias- se encuentran escribiendo desde una perspectiva crítica que corroe las arquitecturas de la colonialidad y sus impulsos de racialización, segregación, desigualdad, e injusticia: es posible imaginar una genealogía anticolonial que recorre el pensamiento y la historia de esta América nuestra que es al mismo tiempo idea, sueño y poder.

\section{Género: posibilidades y dificultades en el horizonte de la tradición anticolonial}

En los últimos años, han visto la luz una serie de trabajos surgidos en torno a la idea de género y sus implicancias en la mantención y la reconfiguración de las relaciones de poder que son depositarias de los legados coloniales que, aún hoy, perviven en nuestro continente.

Autoras como María Galindo -feminista comunitaria boliviana que forma parte de Mujeres Creando-, Yuderkys Espinosa -teórica y activista lesbiana y antirracista que escribe denunciando la violencia que sufren las mujeres negras y migrantes-, María Lugones - filósofa argentina que se encuentra pensando en la relación que surge entre las 
teorías feministas y la descolonialidad- y Karina Bidaseca -académica feminista que trabaja en torno a la noción de descolonialidad-, están trabajando desde miradas que conjugan de manera crítica los desarrollos del concepto género y sus hibridaciones con la colonialidad y, también, con la larga tradición del pensamiento crítico latinoamericano.

A partir de una revisión detallada del trabajo de cada una de estas investigadoras y teóricas feministas, es posible observar que sus formas de acercamiento a las "temáticas de género", difieren ampliamente, sin embargo, si hay algo que todas ellas tienen en común, es que se atreven a revisar los significados de este concepto a fin de tensionarlo y pensarlo desde distintos lugares, dando cuenta de sus potencialidades disrruptivas y también de sus peligros normativos. Así, si algo parece claro a la luz de las preguntas, reflexiones y desafíos que sus trabajos nos plantean, es que las discusiones que nos proponen resultan urgentes y que los estudios anticoloniales ya no pueden mantenerse indiferentes frente a la potencia de los debates que ellas han venido desarrollando.

Resulta llamativo que incluso para autores como Walter Mignolo y Aníbal Quijano el género se haya vuelto un tema de relevancia, o al menos algo que hay que tener en vista en el horizonte de los elementos que conforman y ordenan el mundo. Ambos autores se han visto involucrados en proyectos en los que la palabra género adquiere relevancia. Sin embargo, llama la atención el tratamiento que dan al término y el carácter, con que este concepto aparece tratado en sus escritos, toda vez que es visto como algo siempre transparente y con un significado que, por ser pensado como obvio, se resiste a la revisión. Estos autores se acercan a la idea de género casi como si no fuese necesario revisarla, como si género fuera una palabra con una definición obvia y aceptada sin dificultades. Es decir, pasando por alto las luchas, reapropiaciones y reivindicaciones feministas que han venido desafiando el concepto género desde sus orígenes.

Género, por supuesto, no es un concepto neutro que pueda ser utilizado sin tener en cuenta sus lugares de enunciación y surgimiento, es necesario que nos hagamos cargo de sus dificultades, usos, y posibilidades.

Género es un concepto que surgió al alero de la medicina y su aparición tiene que ver con el desarrollo de protocolos orientados al "tratamiento" y la "normalización" de las personas intersexuales. En su texto, Cuerpos sexuados. La política de género y la construcción de la sexualidad, la bióloga feminista Anne Fausto-Sterling, ha propuesto que fueron los médicos John Money y Anke Ehrhard los primeros investigadores que basados en la suposición de la existencia de un sexo verdadero que antecedería al lenguaje- asumieron la posibilidad de imaginar y articular la categoría de género, como refuerzo y respuesta "natural" de aquello que el cuerpo indica que un sujeto es o debe ser. Según esta autora, ambos doctores argumentaron que el sexo "se refiere a los atributos físicos, y viene determinado por la anatomía y la fisiología, mientras que el género es una transformación psicológica del yo, la convicción interna de que uno es macho o hembra (identidad de género) y las expresiones conductuales de dicha 
convicción" (Fausto-Sterling, Anne. 2000/ $2006 . \quad$ p.18).

En una dirección que refuerza lo anterior, Marta Lamas, directora de la histórica revista Debate feminista, ha señalado que el hecho de que "la diferencia biológica, cualquiera que ésta sea (anatómica, bioquímica, etcétera), se interprete culturalmente como una diferencia sustantiva que marcará el destino de las personas con una moral diferenciada es el problema político que subyace a toda la discusión académica sobre las diferencias entre los hombres y las mujeres" (Lamas, Marta. 2002. p.25).

Walter Mignolo, es el compilador del libro Género y descolonialidad, texto en el cual se pregunta, a modo de introducción, cuáles son los posibles cruces que surgen del encuentro de las nociones de género y (des)colonialidad (Mignolo, Walter: 2003/ 2008, 7). Mignolo propone en este texto -siguiendo a Quijano- que el ordenamiento de los significantes que dan sentido a nuestro horizonte cultural y material, está marcado por una matriz de colonialidad del poder que se organiza en torno a cuatro ejes principales (Mignolo, Walter: 2003/ 2008, 7). Según el análisis propuesto por este autor, el tercero de estos ejes de significación colonial es el "control del género y la sexualidad que incluye la invención del concepto de "mujer" [...]; la heterosexualidad como norma; el modelo de la familia cristiana victoriana como célula social" (Mignolo, Walter: 2003/ 2008, 8).

La idea de invención de las mujeres que propone Mignolo -releyendo, según el mismo señala, a María Lugones y a Madina Tlostanova- sorprende, y, aun cuando en un principio pueda aparecer como algo atractivo, pierde gran parte de su potencia, toda vez que, a lo largo de su trabajo, no es desarrollada por el autor más allá de una explicación bastante simplificada de la forma en que el patriarcado habría actuado -en el tiempo de la conformación imaginaria de las sociedades americanas- como un agente censurador que "regula las relaciones sociales de género y también las preferencias sexuales y lo hace en relación a la autoridad y a la economía, pero también al conocimiento: que se puede/debe conocer quiénes pueden y deben saber" (Mignolo Walter: 2003/2008, 9).

El problema que observamos aquí es que Mignolo, tal como se desprende de la referencia anterior, al asumir y declarar que la identidad "mujer" se articula a través de un carácter ficcionado e inventado, utiliza el concepto de género sin revisar sus supuestos biologizantes, y así, sin quererlo, actúa reinscribiendo sobre los cuerpos de las biomujeres ${ }^{5}$ una diferencia que se configura como ontológica.

\footnotetext{
${ }^{5}$ Utilizo aquí el concepto bio-mujeres para hacer referencia a la distinción entre lo "bio" y lo "tecno" (también imaginado como lo "trans") que propone Beatriz Preciado en su libro Testo Yonki. Aquí la división entre uno y otro estado es, según esta autora, una sexotecnificación que sirve "para denominar respectivamente a aquellas personas que se identifican con el sexo que les ha sido asignado en el nacimiento (bio) y aquellos que contestan esa asignación y desean modificarla con la ayuda de procedimientos técnicos, prostéticos, performativos y/o legales (trans)" (Preciado, Beatriz. 2008. p. 85). Respecto a esta división, Preciado señala que es fundamental reconocerla como construida y artificial, puesto que "ambos estatutos de género (bio y trans) son técnicamente producidos" (Preciado, Beatriz. 2008. p. 85).
} 
Además, es necesario señalar que en el resto de sus textos, Walter Mignolo no vuelve a considerar al género como un asunto que resulte significativo a la hora de buscar explicaciones que nos permitan comprender los procesos de articulación de las subjetividades que se conforman a partir de los procesos ligados a la idea de colonialidad. Es más, ni siquiera menciona el aporte de las feministas descoloniales como espacios de discusión y análisis que pudieran arrojar luces sobre estos puntos.

¿Por qué un análisis que parecía prometedor vuelve a quedarse sólo en la superficie? ¿Por qué Walter Mignolo aparece compilando un texto sobre género y descolonialidad si, al parecer, no está dispuesto a pensar seriamente sobre estos temas y los vuelve a poner en escena solamente en una clave que refuerza "lo natural"?

Sin duda es aquí donde cobran sentido las críticas que este pensador ha recibido de parte de algunas teóricas feministas que se inscriben en el amplio horizonte del pensamiento anticolonialista latinoamericano y Caribeño. Destacando en este sentido autorxs como Yuderkis Espinosa, Rita Laura Segato y Constanzx Alvarez Castillo.

Un caso muy similar es el del sociólogo peruano Aníbal Quijano, quien frente a la necesidad de articular un concepto capaz de englobar la experiencia de la subjetivación colonial, construye la idea de la colonialidad del poder como un eje de reflexión central que aparece desarrollado de forma fragmentada y extendida a lo largo de varios sus escritos $^{6}$. A través de este concepto, Quijano intenta dar cuenta de "uno de los ejemplos clave de esos momentos de bruscas y drásticas mutaciones de la experiencia histórica en el mundo" (Quijano, Aníbal: 2001,120).

Aníbal Quijano utiliza el concepto género como uno de los elementos que, actuando como articulador de significados en nuestro presente, tiene a la colonialidad del poder como sustrato de su estructura subjetiva, de la cual sólo podremos salir una vez que reconozcamos sus raíces y nos atrevamos a desafiarlas. Quijano, así como Mignolo, nombra el concepto de género y lo ubica en un horizonte de "invención" relacionándolo con la colonialidad/modernidad y señalando que "es probable, aunque la cuestión queda todavía por indagar, que la idea de género se haya elaborado después del nuevo y radical dualismo como parte de la perspectiva cognitiva eurocentrista" (Quijano, Aníbal: 2000, 225).

Sin embargo, al igual que Walter Mignolo, este autor no se ocupa de definir este concepto, es más ni siquiera se detiene un momento a explicar los modos en que lo utiliza, dando sus significados por obvios y, por lo tanto, naturalizando sus sentidos y sus alcances. Al igual que en el caso anterior, Quijano asume el género como un término

\footnotetext{
${ }^{6}$ La colonialidad del poder es un concepto fragmetado que está presente de forma transversal en gran parte de la obra de Quijano, aparece en varios textos y artículos de este autor y por tanto, se trata de una idea con elaboraciones y reelaboraciones que le permiten añadir y corregir elementos y revisiones a lo largo de su producción escritural, es decir, desde los años 80 a sus trabajos más recientes.
} 
cerrado sobre sí mismo y acabado, es decir, imagina un concepto cuyas acepciones están dadas al margen de cualquier revisión y más allá de la historia.

¿Cuáles son los peligros que se encierran en el uso no problematizado de los conceptos? ¿Cómo podemos saber realmente a qué se están refiriendo autores como Mignolo y Quijano cuando hablan de género? ¿Por qué no se preocupan de definirlo ni de describirlo? ¿No quedará oculto en este silencio un resquicio para preservar sus propios privilegios?

\section{El feminismo descolonial como clave de análisis}

La urgencia de revisar las lógicas del género y denunciar sus violencias implícitas -que podríamos imaginar cómo relacionadas a lo que Judith Butler ha denominado matriz de intelegibilidad heterosexual (Butler, Judith. 1990/ 2007) y a lo que Beatriz Preciado llama micropolíticas de género en la era farmacopospornográfica (Preciado, Beatriz. 2008)- ha dado paso, entre otras revisiones, a un movimiento crítico que se propone repensar el género y el feminismo.

¿Es posible pensar el género como una herramienta crítica capaz de torcer las estrategias de control y colonialidad que se extienden sobre los cuerpos y las subjetividades de las mujeres en América Latina? ¿Basta incluir la categoría género para abrir paso a una posibilidad disruptiva real, que trastoque los órdenes patriarcales y reconfigure las lógicas del poder?

Me gustaría recordar aquí el título que la historiadora Joan Scott propone para el texto que ella misma elabora con la intención de revisar su ya clásico artículo Género: una categoría útil para el análisis histórico (Scott, Joan. 1986/ 2008), el cual fue publicado por primera vez en 1986. Veinticuatro años más tarde, Scott escribió Género: ¿Todavía una categoría útil para el análisis? (Scott, Joan. 2010/ 2011), denunciando cómo, a partir de la estabilización de los significados del género, el uso de este concepto ha visto comprometido su potencial disruptivo y movilizador en la arena de lo político ${ }^{7}$.

Joan Scott, nos invita a reflexionar sobre los usos no problematizados de los conceptos, señalando que: "cuando creemos conocer lo que un término significa, cuando su empleo es tan comúnmente aceptado que ese significado ya no necesita ser atribuido, entonces es cuando necesitamos de nuevas palabras y nuevos conceptos" (Scott, Joan: 2008, 15), o

\footnotetext{
${ }^{7}$ En este texto la autora señala: "Para mediados de los 90 s, al menos en Estados Unidos, el término género parecía haber perdido su filo crítico precisamente porque su significado parecía poder tomarse por establecido. La palabra ya no era desconcertante, ya no ofrecía un reto al uso gramatical fijo; por el contrario, era un término más o menos generalmente entendido del léxico feminista. Por supuesto, tal no era el caso de otras partes del mundo no de habla inglesa. En esos lugares la misma dificultad para traducir la palabra daba un cierto cuestionamiento radical asociado con el feminismo. También ocasionaba el rechazo firme de las autoridades, quienes condenaban la palabra por inapropiada, inaceptable, inclusive inculto, porque caía fuera de los límites nacionales de "uso común" (Scott, Joan. 2010/ 2011. p. 98).
} 
al menos, una reconstitución crítica de los mismos, a fin de no construir en torno a ellos, miradas esencialistas, naturalizantes e inmovilizadoras.

Es justamente en atención a lo anterior, que Marta Lamas ha planteado que tal parece ser que "cruzar el umbral del género para arriesgarse a pensar las implicaciones de esa diferencia insondable del cuerpo es el actual desafío de un pensamiento crítico feminista" (Lamas, Marta: 2002, 14). Es decir, atreverse a revisar el concepto de género para observar no sólo sus usos sino también sus dificultades e incluso sus trampas es una tarea fundamental, si lo que queremos es llevar adelante un análisis que no refuerce las categorías identitarias binarias que ordenan a los cuerpos en el marco regulatorio biologicista de lo considerado normal.

Desde el feminismo descolonial, distintas voces cuestionan los imaginarios surgidos al amparo de las teorías feministas blancas hegemónicas que, según han señalado Karina Bidaseca y Vanesa Vazquez, desde argentina, "interpretan las prácticas culturales de las mujeres subalternas como residuos arcaicos; las representan como inmaduras para la praxis política $y$, por tanto, justifican la necesidad de ser "educadas" en el feminismo occidental" (Bidaseca, K y Vazquez, V: 2011, 1).

El feminismo descolonial es una apuesta epistemológica imaginada desde el Sur, a través de la cual mujeres y sujetos situadxs en los márgenes del género y de las prácticas feministas hegemónicas intentan elaborar vías alternativas de significación y reconfiguración identitaria, a través de la reivindicación de las nociones de experiencia y diferencia. Fundamentales para la formación de este campo crítico feminista han resultado las experiencias surgidas al alero de los movimientos feministas negros -en sus corrientes inglesa, estadounidense y de la diáspora- así como también las acciones y reflexiones nacidas desde las mujeres de color.

Pensar la identidad, desde la perspectiva de las formaciones críticas que se han propuesto desde los feminismos descoloniales, es articular un complejo cruce de referencias que se intersectan y que conforma un entramado indivisible de valoraciones que posicionan a los sujetos en el marco de lo inteligible. La idea de interseccionalidad adquiere un lugar de máxima relevancia a la hora de pensar las formas en las que las experiencias que nos atraviesan configuran nuestro estar en el mundo. Se trata de un estar en el mundo que se ubica en un más allá del género, más allá de la clase, más allá de la raza, justamente porque no puede ser apartado ni separado de ninguno de estos componentes.

Esta posición se alía con las propuestas de autoras como bell hooks, quien señala acertadamente que "si bien resulta evidente que muchas mujeres sufren la tiranía sexista, hay pocos indicios de que este hecho forje "un vínculo común entre todas las mujeres». Hay muchas pruebas que demuestran que las identidades de raza y clase crean diferencias en la calidad, en el estilo de vida y en el estatus social que están por encima de las experiencias comunes que las mujeres comparten; y se trata de diferencias que rara vez se trascienden" (hooks, bell: 2004, 37). 
La necesidad de revisar las formas en que las desigualdades de género interactúan con otras variables, como por ejemplo raza y clase, constituyen uno de los puntos centrales que caracteriza las propuestas surgidas desde los feminismos descolonizadores. La situación antes descrita, cobra, para América latina y el Caribe, una relevancia que es clave y que nos obliga a repensar histórica y epistemológicamente los giros y propuestas que han surgido en el marco de la tradición anticolonial.

La lucha aquí debiera ser no sólo de las feministas tercermundistas que se han propuesto la tarea de dar cuenta del etnocentrismo del feminismo occidental, sino más bien revelar las implicancias colonialistas del sistema de género en general, tal como ha propuesto María Lugones en su fantástico texto Hacia un feminismo descolonial (Lugones, Maria. 2011).

Aquí la autora señala que lo que importa no es tanto incluir el concepto género entendido únicamente como una diferencia cultural que expresa las diferencias biológicas existentes entre hombres y mujeres- como un asunto a tomar en cuenta a la hora de pensar en la matriz de intelegibilidad colonial impuesta sobre nuestros territorios, sino más bien comprender los modos en que éste ha operado y sigue operando como motor productor de la desigualdad. Lugones se pregunta, releyendo de forma cómplice a Oyeronke Oyewuni (Lugones, María. 2011. p.111), si es que acaso las estructuras de género ya existían en nuestros territorios americanos antes de la imposición colonial.

Siguiendo lo anterior, y a modo de síntesis, quizás sería interesante preguntarnos sobre los modos en los que es posible incluir la categoría de género como un conjunto de sentidos que resulten útiles para la revisión de las realidades latinoamericanas y caribeñas, entendiendo que, por muy buenas que sean nuestras intenciones, al parecer no bastaría sólo con nombrarlas y agregarlas como un asunto a tener en cuenta, si es que no estamos dispuestos a revisar, realmente y a fondo, su historicidad y sus efectos en la articulación en los mecanismos que producen y refuerzan las desigualdades y las injusticias que construyen nuestros horizontes de representación corporal y subjetiva.

\section{Nunca dejar de mirar...}

Habitamos historias que han sobrevivido a los embistes coloniales. Habitamos un tiempo en el que "las palabras no designan, sino que encubren" (Rivera Cusicanqui, Silvia. 2015. p.175). Nuestro tiempo guarda en su interior la potencia de un Sur que se resiste a olvidar y a abandonarse. Habitamos historias y tiempos que están llamadas a "resistir a la violencia epistémica, a la prohibición de explicarse el mundo con códigos y referencias propias, inoculando preguntas incestuosas como ¿quién tiene permiso de narrar? ¿Quién relata? ¿Quién pone en circulación los relatos? ¿Quién es el ventrílocuo de nuestras voces?" (Flores, valeria. 2016. p.239) 
¿Cómo interrogar el Sur y nuestra historia sin reforzar, por omisión, los mecanismos de sujeción e inteligibilidad que nos han construido? ¿Cómo incluir el género como una categoría de análisis que aparezca integrada -y no al margen- de las ideas y reflexiones que se enmarcan en el amplio horizonte de lo anticolonial latinoamericano? ¿Basta con decir género, o es necesario desmontar esta categoría para evitar caer en naturalizaciones que desaten efectos perversos?

Urge revisar de forma interseccional y comprometida todos los mecanismos de poder que operan en nuestros procesos de articulación subjetiva. No podemos dejar nada en el margen, no podemos pensar que hay asuntos más importantes que otros o que el género es un asunto que afecta y debiese ocupar exclusivamente a las mujeres. El desmontaje debe realizarse en la práctica, en la búsqueda de nuevos escenarios de apropiación de la palabra, de los saberes, de nuestros cuerpos.

Debemos hacernos de nuestras propias historias borroneadas y montadas por la fuerza, escuchar el dolor, sanar nuestras heridas e inventar nuevas formas de contarnos el mundo y de encontrarnos. Debemos insistir en la denuncia de las tramas de la dominación y en la denuncia cotidiana de sus estructuras entrecruzadas.

No podemos pensar América Latina y el Caribe sin pensar los procesos de colonización que construyeron y ordenaron a los sujetos en función de una arquitectura social caracterizada por las desigualdades de raza. No podemos pensar la raza sin el género, porque de lo contrario estaríamos ocultando un conjunto de violencias que son también urgentes.

Finalmente, no podemos pensar el género sin dar cuenta de los imaginarios feministas y sus luchas, porque el género a secas trae consigo el peligro de la indefinición y la invisibilización forzada de aquello que se ubica más allá de sus fronteras.

\section{BIBLIOGRAFÍA}

Bidaseca Karina y Vasquez Vanesa (comp) (2011). Feminismos y poscolonialidad. Descolonizando el feminismo desde y en América Latina. Buenos Aires: Ediciones Godot Argentina.

Bidaseca Karina y Vasquez Vanesa (2011). Feminismos y (des)colonialidad. Las voces de las mujeres indígenas del sur. En: Temas de Mujeres. Año 7. № 7.

Butler, Judith (1990/2007). El género en disputa. El feminismo y la subversión de la identidad. Buenos Aires: Paidós.

Castro-Gomez, Santiago et all (ed.) (1999). Pensar (en) los intersticios. Teoría y práctica de la crítica. Bogotá: Centro Editorial Javierino. 
De Sousa Santos, Boaventura (2009). Una epistemología del sur: la reinvención del conocimiento y la emancipación social. Buenos Aires: Siglo XXI editores.

Espinosa, Yuderkys (2014). Una crítica descolonial a la epistemología feminista crítica. En: Cotidiano 184. marzo-abril.

Federicci, Silvia (2011). Calibán y la bruja. Mujeres Cuerpo y acumulación originaria. Buenos Aires: Tinta limón.

flores, Valeria (2016). La intimidad del procedimiento. Escritura, lesbiana, sur como prácticas de sí, en: Badebec - VOL. $6 N^{\circ} 11$ (Septiembre 2016) ISSN 1853-9580/ valeria flores.

Gargallo, Francesca (2014). Feminismos desde Abya Yala. Ideas y proposiciones de las mujeres de 607 pueblos en nuestra América. Ciudad de México: Editorial Corte y Confección.

hooks, bell, et all. (2004). Otras inapropiables. feminismos desde las fronteras. Madrid: Traficantes de sueños.

Jabarda, Mercedes (ed.) (2012). Feminismos negros. Una antología. Madrid: Traficantes de sueños.

Lamas, Marta (2002). Cuerpo: diferencia sexual y género. México D.F: Taurus.

Lugones, Maria (2005). Multiculturalismo radical y feminismos de mujeres de color, en: RIFP / 25. pp. 61-75

Lugones, Maria (2011). Hacia un feminismo descolonial. En: La manzana de la discordia, Julio - Diciembre, Vol. 6, No. 2: 105-119.

Lugones, Maria (2008). Colonialidad y género, en: Tábula raza, Bogotá-Colombia, № 9, p. 73-101.

Mignolo, Walter (2007). La idea de América Latina. La herida colonial y la opción decolonial. Barcelona: Gedisa.

Mignolo, Walter (comp.) (2003). Género y descolonialidad. Buenos Aires: Del signo.

Palermo, Zulma y Quintero, Pablo (2014). Aníbal Quijano. Textos de fundación. Buenos Aires: Del signo.

Preciado, Beatriz (2008). Testo Yonki. Madrid: Espasa-Calpe. 
Posada, Luisa (2010). Igualdad, epistemología y género: desde un horizonte ético-político. En: Quaders de psicología. vol. 12. No2. pp. 81-91.

Quijano, Aníbal (2014). Cuestiones y Horizontes. De la Dependencia Histórico-Estructural a la Colonialidad/Descolonialidad del Poder. Buenos Aires: Clacso.

Quijano, Anibal (2001). Colonialidad del poder, cultura y conocimiento en América latina. En: Walter Mignolo. (Comp.). Capitalismo y geopolítica del conocimiento. El eurocentrismo y la filosofía de la liberación en el debate intelectual contemporáneo, p118-131. Buenos Aires: Del signo.

Quijano, Anibal (2000). Colonialidad del poder, eurocentrismo y América Latina. en: Edgardo Lander, La colonialidad del saber: eurocentrismo y ciencias sociales. Perspectivas Latinoamericanas, p122-151. Buenos Aires: CLACSO.

Rivera Cusicanqui, Silvia (2015). Sociología de la imagen. Miradas ch'ixi desde la historia andina. Buenos Aires: Tinta limón.

Scott, Joan (2008). Género e Historia. Mexico D.F.: Fondo de cultura económica.

Scott, Joan. (2010/ 2011). Género: ¿Todavía una categoría útil para el análisis?. En: La manzana de la discordia, Enero-Junio, vol. 6, No 1: 95-101.

Suárez, Liliana y Hernández, Rosalva (2008). Descolonizando el Feminismo: Teorías y Prácticas desde los Márgenes. Madrid: Cátedra.

Wittig, Monique (2006). El pensamiento heterosexual y otros ensayos. Madrid: Egales. 